The relationships among perceived work stress, subjective well-being, and depression: Proactive coping as a mediator

\author{
Yu, Min-Ning \\ National Cheng-Chi University, Taiwan (mnyu@nccu.edu.tw) \\ Hung, Chao-Hsiang \\ National Cheng-Chi University, Taiwan(aka0518@gmail.com) \\ Lin, Chung-Wei \\ National Cheng-Chi University, Taiwan (cwlin2012@gmail.com)
}

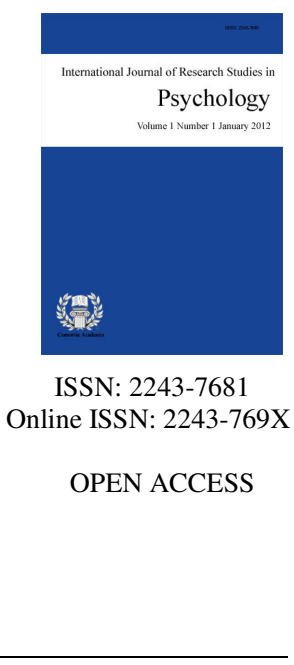

\title{
Abstract
}

Teachers have high work stress such as longer work hours and the student problems, but the perceived work stress has different effects. In some case, perceived work stress may lead teachers to the physical and psychological problems. Comparatively, some teachers regard the stress as a challenge and the engine of growth and resources. In this study, our purpose was to understand what perceived work stress (PWS) effects on subjective well-being (SWB) and depression, and we also examined the mediating role of proactive coping (PC) between PWS to SWB and depression. Results showed that 1) Significant relationships existed among PWS, SWB, PC, and depression. 2) PWS from students, parents, had significantly caused depression and SWB. 3) PC successfully mediated the relationships from the PWS to depression and SWB. Our hypothesis of mediation had been supported. The current study hoped that the findings would be able to help educational administrators, policy makers, and researchers in protecting teachers' mental health.

Keywords: perceived work stress; subjective well-being; depression; proactive coping 


\section{The relationships among perceived work stress, subjective well-being, and depression: Proactive coping as a mediator}

\section{Introduction}

It's not what happens to you, but how you react to it that matters.

By Epictetus (AD 55-135)

Being a teacher, there were lots of working stress from students, parents, and school. About teacher's work stress, there are different kinds of sources include over workload such as longer working hours and overloaded classes, insufficient resources such as the lack of educational resources, lack of supervisor support and poor working conditions, and a daunting task such as disruptive students, red tape and the changing education policies (Burke, Greenglass, \& Schwarzer, 1996; Eres \& Atanasoska, 2011; Kyriacou, 1987; Kyriacou \& Chien, 2004; Zedan, 2012). Previous studies in Taiwan pointed out teachers suffering from longer working hours expose to higher risk of depression. If the teachers have high subjective well-being, they have the low risk of depression (Yu, Syu, \& Chen, 2010). It showed that working stress did not always cause negative outcomes, and it depended on other factors to mediate. In this study, our purpose was to understand what perceived work stress (PWS) effects on subjective well-being (SWB) and depression. Furthermore, the mediating role of proactive coping (PC) was also examined, and we assume proactive coping was the key to preventing teachers' suffering from work stress.

\subsection{Work Stress and Depression}

Teachers have high perceived work stress and it has related to lots of physical problems and mental illness (Burke, Greenglass, \& Schwarzer, 1996; Kokkinos, 2007; Kyriacou, 1987, 2001; Kyriacou \& Chien, 2004) such as chronic fatigue, heart problem, muscle tension, alcohol abuse, work strained anxiety and accidents. When individual cannot handle work stress and feel imbalance, it might become burnout and then develop into depression (Ashforth \& Lee, 1997; Cooper, Dewe, \& O'Driscoll, 2001; Cordes, Dougherty, \& Blum, 1997; Golembiewski, Boudreau, Goto, \& Murai, 1993; Hopkins, Hoffman, \& Moss, 1997; Maslach, Schaufeli, \& Leiter, 2001; Rossi, Perrewe, \& Sauter, 2006; Tennant, 2001). We should pay attention to teachers' work stress and find ways to reduce it.

\subsection{Work Stress and Subjective Well-Being}

There are many definition and concept of well-being. In this study, subjective well-being is a three component structure, including emotional well-being (EmoWB), psychological well-being (PsyWB), and social well-being (ScoWB). The emotional well-being was named by Keyes (1998, 2002, 2005), and its content was consistent with the subjective well-being which proposed by Diener $(1984,2000)$ including positive affect and life satisfaction. The psychological well-being has six concepts, namely self-acceptance, positive relations with others, autonomy, environmental mastery, purpose in life, and personal growth (Ryff, 1989, 1995; Ryff \& Keyes, 1995). The social well-being means having the good function in the interpersonal society and community (Keyes, 1998, 2002, 2005; Keyes \& Magyar-Moe, 2003). It measured by five contents, namely social integration, social acceptance, social contribution, social actualization, and social coherence (Keyes, 1998). As mentioned above work stress might cause negative emotional, physical and psychological problems, it might also damage subjective well-being. 


\subsection{Coping}

Working in a busy modern society, teachers will inevitably feel the work stress, but different coping strategies bring different results. As the stress aroused emotional and physiological reactions, it made people uncomfortable. In order to reduce such uncomfortable state, people took some action, which is called coping. Traditional coping theory focused on when the stressful event occurs what type of individual coping strategies will be used. Lazarus and Folkman (1984) proposed Cognitive-Appraisal Model include two kinds of coping type that are problem-focused coping and emotion-focused coping. The problem-focused coping strategies put attention on problems and try to seek the solution and carry out. The emotion-focused coping strategies try to ease the emotion when the situation cannot be changed. These two kinds of strategies are not independent and most people use both of them.

Schwarzer (2000) recommend coping strategies should not be reduced to relaxation and fight-or-flight and it should be considered the time perspective and subjective certainty. The new perspectives distinguish four different types of coping namely reactive coping, anticipatory coping, preventive coping, and proactive coping. Schwarzer and Knoll (2003) point out proactive coping is a kind of positive coping. The individual who takes proactive coping will seek to opportunities, requirements and challenges, and they do not regard stress as a threat, but as a personal challenge. Differ from the traditional theory, the proactive coping is not to resist the negative events (stress), but an active and positive behavior including building personal resources, improving individual skills and strategies, learning mastering demand, and searching for meanings (Folkman \& Moskowitz, 2000, 2004; Lararus, 1991; Schwarzer, 2000; Schwarzer \& Knoll, 2003).

\subsection{Coping, Depression, and Subjective Well-Being}

Using proactive coping makes people's psychological health, life quality, and social function better (Schwarzer \& Knoll, 2003; Yanos, 2001). The proactive coping has the positive relationship with self-efficacy and negative relationship with burnout (Greenglass 2002) and lower anxiety level (Raffety, Smith, \& Ptacek, 1997). In this study, we expect that teacher with proactive coping had better subjective well-being (SWB) and lower depression.

\section{Materials and Methods}

\subsection{Research Design}

We used a cross-sectional and quantitative data collection method in this study. Self-reported questionnaires were applied to measure the latent variables, test the hypotheses and infer the associations of relationships among the latent variables.

\subsection{Theoretical model and hypotheses}

This framework primarily builds on the positive psychology, mental health on workplace, and the concept of depression. It is hypothesized that the new model of SWB between perceived work stress and depression for Taiwan teachers. We had taken perceived work stress (PWS) as latent IV, proactive coping (PC) as latent mediator, subjective well-being (SWB) and Depression as latent DV, and five hypotheses were stated as following (see Fig. 1).

$>$ Hypothesis 1. PWS has a significant negative effect on PC.

$>\quad$ Hypothesis 2. PC has a significant positive effect on SWB.

$>\quad$ Hypothesis 3. PC has a significant negative effect on Depression. 
$>$ Hypothesis 4. PC mediates the relationship between PWS and SWB.

$>$ Hypothesis 5. PC mediates the relationship between PWS and Depression.

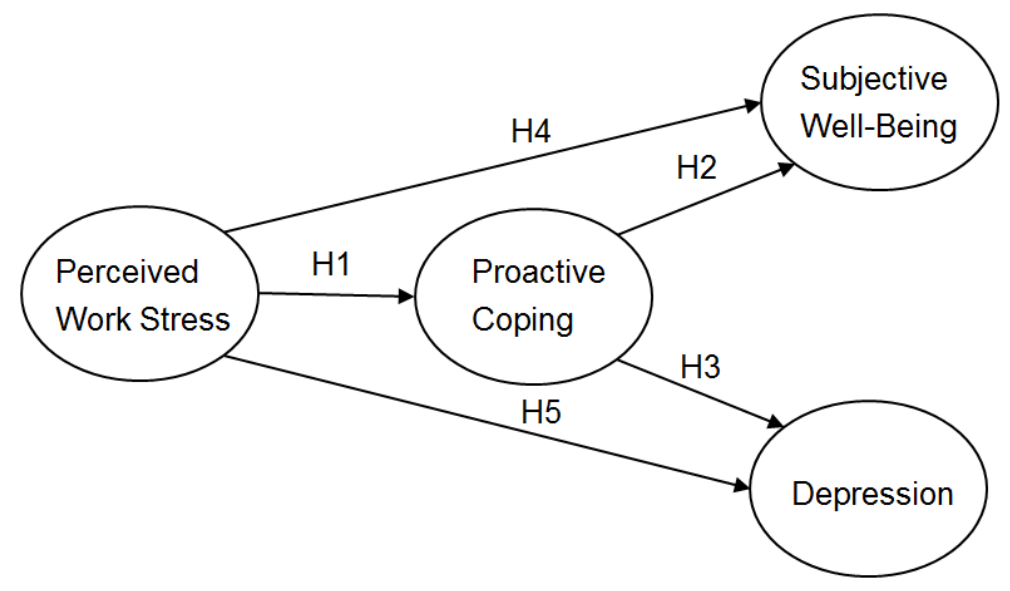

Figure 1. Hypothesized mediated model

\subsection{Participants}

This study involved 1143 Taiwan teachers enrolled in different level schools from primary school (70.0\%), junior high school (20.1\%), high school (6.2\%), and vocational school (3.7\%). The sample included $40.7 \%$ male and $59.2 \%$ female. Of the participants, $58.9 \%$ were tutors, $13.7 \%$ were subject teachers, and $26.4 \%$ were with administrative position. Most part of teachers has bachelor degree (46.3\%) and master degree (52.6\%).

\subsection{Measures}

Perceived Work Stress (PWS) - PWS has been used to describe how much loading teachers are suffering. Two items were used to measure the latent variable PWS, including the perceived work stress from students and parents (Chung, Yu, Syu, Chen, \& Chao, 2013). Items were 4-points Likert's scale ranging from 1 to 4. Higher point means more loading teachers perceived. Three items are reliable and valid, the Cronbach's alpha was .66, and the explained variance was $60.4 \%$.

Subjective Well-Being (SWB) - SWB was measured by short form edition of Subjective Well-Being Scale with three factors, including Psychological Well-Being (PsyWB), Social Well-Being (SocWB), and Emotional Well-Being (EmoWB) (Yu, Hsieh, Lin, Chen, \& Tseng, 2011). All items are 4-points Likert's scale ranging from 1 to 4. Higher scores on the SWB indicated higher levels of SWB. The Cronbach's alpha ranging from .63 .86, and the explained variance ranging from $40.2 \% \sim 71.1 \%$.

Depression (DEP) - DEP was measured by Taiwan Depression Scale (TDS), the local scale developed for collecting data of Taiwan people's mental disease (Yu, Huang, \& Liu, 2011; Yu, Liu, \& Li, 2008). There are four factors within TDS, such as Cognitive Depression (CogD), Emotional Depression (EmoD), Physical Depression (PhyD), and Interpersonal Depression (IntD). All items were 4-point scale ranging from 0 to 3 . Higher scores on the TDS indicated higher levels of DEP. The Cronbach's alpha ranging .81 .89, and the explained variance ranging $51.7 \% \sim 65.5 \%$.

Proactive Coping (PC) - PC was measured by Proactive Coping Scale (PCS), developed by Greenglass et al. (1999), has been examined in various samples and is available in several languages (Schwarzer \& Knoll, 2003). The PCS consisted of 14 items. Respondents were asked to rate each statement on a 4-point Likert scale. Higher scores on the PCS indicated higher levels of proactive coping. The Cronbach's alpha was .90, and the explained variance was $50.6 \%$. In order to balance the number of items in every latent variable and lower the complexity of computation, three items with highest factor loading were selected (see table 1). 


\subsection{Data analysis}

The sample had been separated into two parts by random ( $33 \%$ sample, $n=377 ; 67 \%$ sample, $n=766)$. The $33 \%$ sample used in measurement model (confirmatory factor analysis, CFA), the other $67 \%$ sample used in structure model (structure model and mediation test). Descriptive statistics, ANOVA and correlation estimated using SPSS 21 program, composite reliability (CR) and average variance extracted (AVE) were used to prove the reliability and validity of measurement model. Structure model was used to explaining the relationship and effects among latent variables. Structure equation modeling (SEM) was used with the maximum-likelihood estimation method in the AMOS 20 program (Arbuckle, 2011).

\section{Results}

\subsection{Preliminary Analyses}

Means, standard deviations, and zero-order correlations for the 12 measured variables are shown in Table 1. Because the number of item were not equal in every variable, we used mean to represent. All the means of observed variables ranged $.46 \sim 3.09$, SD ranged $.38 \sim .73$. Multivariate normality test was used to examine whether the data met the normality assumptions underlying the maximum-likelihood procedure used to test the models in the present study. The results of the multivariate normality test indicated that the data were multivariate normal, multivariate kurtosis was 20.81. Therefore, maximum-likelihood method was appropriate.

\subsection{Measurement Model}

Before a structural model is tested, Anderson and Gerbing (1988) suggested conducting a confirmatory factor analysis to examine whether the measurement model provides an acceptable fit to the data. Once an acceptable measurement model is developed, the structural model can be tested. As suggested by Byrne (2009), $\mathrm{Hu}$ and Bentler (1999), Tucker and Lewis (1973), five fit indices were used to assess goodness-of-fit for the models: the goodness-of-fit index(GFI; values $>0.90$ indicate good fit), the comparative fit index (CFI; values $>0.90$ indicate good fit), the Tucker-Lewis Index (TLI; values $>0.90$ indicate good fit), the non-normed fit index(NNFI; values $>0.90$ indicate good fit), and the root-mean-square error of approximation (RMSEA; values $<0.08$ indicate good fit). A test of the measurement model resulted in a relatively good fit to the data $(\chi 2=$ $\left.140.76^{* * *}, \mathrm{df}=48, \mathrm{GFI}=.94, \mathrm{CFI}=.95, \mathrm{TLI}=.93, \mathrm{NFI}=.93, \mathrm{RMSEA}=.071\right)$. All of the standardized loadings of the measured variables on the latent variables were statistically significant $(p<.001$, see Table 3 ). CR of latent variables ranged .71 .85, AVE ranged .45 .64, both CR and AVE fit to the standard suggest by Fornell and Larcker (1981) and Hair et al (2010). Therefore, all of the latent variables appear to have been adequately operationalized by their respective indicators. In addition, correlations among the independent latent variables, the mediator latent variable, and dependent latent variables were all statistically significant $(p<.001$, see Table 4).

\subsection{Structural Model for Testing Mediated Effects}

We had taken Perceived Work Stress (PWS) as latent IV, Subjective Well-Being (SWB) as latent mediator, and Depression (DEP) as latent DV. The results shows a good fit of the model to the data $(\chi 2=151.74 * * *, \mathrm{df}=$ $45, \mathrm{GFI}=.97, \mathrm{CFI}=.97, \mathrm{TLI}=.96, \mathrm{NFI}=.96, \mathrm{RMSEA}=.055)$. Path effect is frequently referred to as direct effect. All the effect size of structural paths were medium and significant $(p<.001$, see Table 5). MacKinnon, Lockwood, Hoffmann, West, and Sheets (2002) assessed many approaches to examine mediation considering Type I error and statistical power. Found the most often used strategy by Baron and Kenny (1986) has the least power (both $\gamma 11$ and $\beta 1$ have to be significant). Then, many studies using this approach have relied on the Sobel test (1982) to examine the significance of mediation effect ( $\gamma 11 * \beta 1$ have to be significant). However, there is evidence that the distribution of mediation effect is not normal (Bollen \& Stine, 1990; MacKinnon \& Dwyer, 1993; Stone \& Sobel, 1990), and the utilization of a significance test, such as the Sobel test, which assumes a normal distribution when examining the mediation effect, is not appropriate. Most recently, Shrout and Bolger 
Yu, M.-N., Hung, C.-H., \& Lin, C.-W.

(2002) suggest bootstrap method can be a better way to examine mediation. Bootstrap method acquires $95 \%$ confidence intervals $(\mathrm{CI})$ for the indirect effect by resampling procedure. Based on central limit theorem, bootstrap method is robust even the distribution of mediation effect is not normal.

Table 1

Means, standard deviations, and zero-order correlations matrix (all sample, $n=1143$ )

\begin{tabular}{llllllllllllll}
\hline & $M$ & $S D$ & 1 & 2 & 3 & 4 & 5 & 6 & 7 & 8 & 9 & 10 & 11 \\
\hline 1.PWS-students & .87 & .70 & 1 & & & & & & & & & & \\
2.PWS-parents & .77 & .73 & .60 & 1 & & & & & & & & \\
3.PC-1 & 2.89 & .59 & -.17 & -.14 & 1 & & & & & & & \\
4.PC-2 & 2.82 & .59 & -.18 & -.14 & .73 & 1 & & & & & & \\
5.PC-3 & 2.83 & .57 & -.22 & -.17 & .48 & .49 & 1 & & & & & \\
6.PsyWB & 2.96 & .40 & -.26 & -.24 & .36 & .36 & .38 & 1 & & & & \\
7.SocWB & 3.09 & .38 & -.15 & -.16 & .24 & .21 & .21 & .56 & 1 & & & \\
8.EmoWB & 2.80 & .54 & -.29 & -.24 & .36 & .39 & .38 & .56 & .44 & 1 & & \\
9.CogD & .46 & .38 & .27 & .24 & -.25 & -.28 & -.29 & -.48 & -.40 & -.49 & 1 & & \\
10.EmoD & .90 & .45 & .35 & .30 & -.18 & -.22 & -.21 & -.41 & -.31 & -.46 & .71 & 1 & \\
11.BioD & .90 & .49 & .28 & .28 & -.19 & -.22 & -.22 & -.36 & -.29 & -.43 & .56 & .69 & 1 \\
12.SocD & .75 & .57 & .22 & .22 & -.21 & -.23 & -.22 & -.37 & -.34 & -.44 & .55 & .53 & .57 \\
\hline & Note. All values of correlation are significant $(p<.001)$. & PC-1: After attaining a goal, I look for another, more challenging one. & \\
\multicolumn{1}{l}{ PC-2: I like challenges and beating the odds. } & PC-3: I always try to find a way to work around obstacles; nothing really stops me.
\end{tabular}

Table 2

Model fit indices

\begin{tabular}{lccc}
\hline \multicolumn{1}{c}{ Indices } & $\begin{array}{c}\text { Measurement } \\
\text { model }\end{array}$ & Structural model & Criteria \\
\hline $\mathrm{N}$ & 380 & 763 & \\
$\chi 2$ & $140.76 * * *$ & $151.74 * * *$ & \\
$\mathrm{df}$ & 48 & 45 & \\
\hline GFI & .943 & .967 & $>.90$ \\
$\mathrm{CFI}$ & .950 & .972 & $>.90$ \\
$\mathrm{TLI}$ & .931 & .960 & $>.90$ \\
$\mathrm{NFI}$ & .926 & .961 & $>.90$ \\
RMSEA & .071 & .055 & $<.08$ \\
\hline Note. $* * * *<<.001$. & & &
\end{tabular}

Table 3

Factor loadings for the measurement model (33\% sample, $n=377$ )

\begin{tabular}{|c|c|c|c|c|c|}
\hline Factor and Item & $\begin{array}{l}\text { Standardized } \\
\text { factor loading }\end{array}$ & $S E$. & $T$ & $A V E$ & $C R$ \\
\hline Perceived Work Stress (PWS) & & & & .63 & .77 \\
\hline from students & .83 & & & & \\
\hline from parents & .75 & 0.13 & 7.09 & & \\
\hline Subjective Well-Being (SWB) & & & & .45 & .71 \\
\hline PsyWB & .73 & & & & \\
\hline SocWB & .55 & 0.08 & 9.14 & & \\
\hline EmoWB & .72 & 0.12 & 11.26 & & \\
\hline Depression (DEP) & & & & & \\
\hline $\operatorname{Cog} \mathrm{D}$ & .80 & & & .59 & .85 \\
\hline EmoD & .85 & 0.07 & 17.05 & & \\
\hline PhyD & .75 & 0.08 & 15.11 & & \\
\hline IntD & .65 & 0.09 & 12.72 & & \\
\hline Proactive Coping (PC) & & & & & \\
\hline PC-1 & .85 & & & .64 & .84 \\
\hline PC-2 & .86 & 0.06 & 16.57 & & \\
\hline PC-3 & .67 & 0.06 & 13.53 & & \\
\hline
\end{tabular}


Relationships among perceived work stress, subjective well-being, and depression: Proactive coping as mediator

Table 4

Correlations matrix for the measurement model (33\% sample, $n=377$ )

\begin{tabular}{llcc}
\hline \multicolumn{1}{c}{ Latent Variables } & 1 & 2 & 3 \\
\hline 1.Perceived Work Stress (PWS) & 1 & & \\
2.Subjective Well-Being (SWB) & -.37 & 1 & 1 \\
3.Depression (DEP) & .45 & -.68 & -.32 \\
4.Proactive Coping (PC) & -.25 & .54 & \\
\hline
\end{tabular}

As Shrout and Bolger's (2002) suggestion, if the 95\% CI for the estimates of the indirect effects based on these 5000 indirect effect estimates does not include zero, then it can be concluded that the indirect effect is statistically significant at the .05 level. Therefore, after the structural models were examined through the AMOS 20 program, the bootstrap procedure was used to test whether or not the indirect effects were statistically significant.

Mediation effect is frequently referred to as indirect effect. The indirect effect from PWS to SWB is -.123. The $95 \% \mathrm{CI}$ for the estimates of the indirect effects ranged -.174 -.077 does not include zero, and then it can be concluded that the indirect effect is statistically significant at the .05 level. For teachers in Taiwan, PC plays a role as mediator between PWS and SWB. Total effect is the summation of direct effect and indirect effect, the total effect from PWS to SWB is -.40, the $95 \%$ CI for total effects ranged -.468 -.312 does not include zero, the total effect is statistically significant at the .05 level. The data shows a good explained variance on SWB. The indirect effect from PWS to depression is .07 . The $95 \%$ CI for the estimates of the indirect effect ranged .043 .106 does not include zero, and then it can be concluded that the indirect effect is statistically significant at the .05 level. For teachers in Taiwan, PC plays a role as mediator between PWS and depression. However, because of small effect size, the meaning of the mediator must be interpreted carefully. The total effect from PWS to depression is .403 , the $95 \%$ CI for total effects ranged $.322 \sim .486$ does not include zero, the total effect is statistically significant at the .05 level. The data shows a good explained variance on depression.

\section{Table 5}

Bootstrap Analysis of Structural Model (67\% sample, $n=766)$

\begin{tabular}{clcc}
\hline Hypothesis & \multicolumn{1}{c}{ Path } & Standardized coefficient & 95\% CI \\
\hline H1 & PWS $\rightarrow$ PC & $-.24 * * *$ & \\
H2 & PC $\rightarrow$ SWB & $.51^{* * *}$ & \\
H3 & PC $\rightarrow$ Depression & $-.29 * * *$ & -.12 \\
H4 & PWS $\rightarrow$ PC $\rightarrow$ SWB & .07 & $-.174 \sim-.077$ \\
H5 & PWS $\rightarrow$ PC $\rightarrow$ Depression & -.40 & $.043 \sim .106$ \\
& Total effect on SWB & .40 & $-.468 \sim-.312$ \\
& Total effect on Depression & & $.322 \sim .486$ \\
\hline Note. $* * * p<.001$. & &
\end{tabular}

\section{Conclusions}

In this study, we use the structured equation modeling in providing the relation between the perceived work stress (PWS), proactive coping (PC), subjective well-being (SWB), and depression (DEP) for Taiwan teachers. The results of the structure model have shown that the proactive coping was a mediator between perceived work stress and subjective well-being, and it was also a mediator between perceived work stress and depression. The test of mediation indicts that proactive coping could be the core role in increasing SWB and decreasing depression. In addition, according to Baron and Kenny (1986), two paths of direct effect is still significant, two mediation paths in our model are partial mediation, shown there may be other effective mediators can be taken into consideration in the future.

The aim of the present study is to explore the effect of proactive coping. The result indicates if someone takes proactive coping to face work stress, their subjective well-being will increase and depression will decrease. The effect of stress causes the negative emotion and reaction, but using the proactive coping it becomes positive 
emotion and reaction. How does the effect of the proactive coping work? According to the Inverted-U model also called the Yerkes-Dodson Law (Muse, Harris, \& Feild, 2003; Yerkes, \& Dodson, 1908), when the stress is low, people feel boredom and the performance are poor, too. When the stress is moderate, people have the best performance. When the stress reaches over a certain level, the performance has decreased. This theory pointed out an area of best performance when optimum stress happened (see the solid curve in Fig. 2). The proactive coping seems to be able to expand the range of optimum stress. At the same time, the area of best performance also seems to expand (see the gray area in Fig. 2). This is the reason people using the proactive coping will not feel negative emotions and have negative performance when they are in high stress. They can maintain high performance under high stress (see the dotted line in Fig. 2).

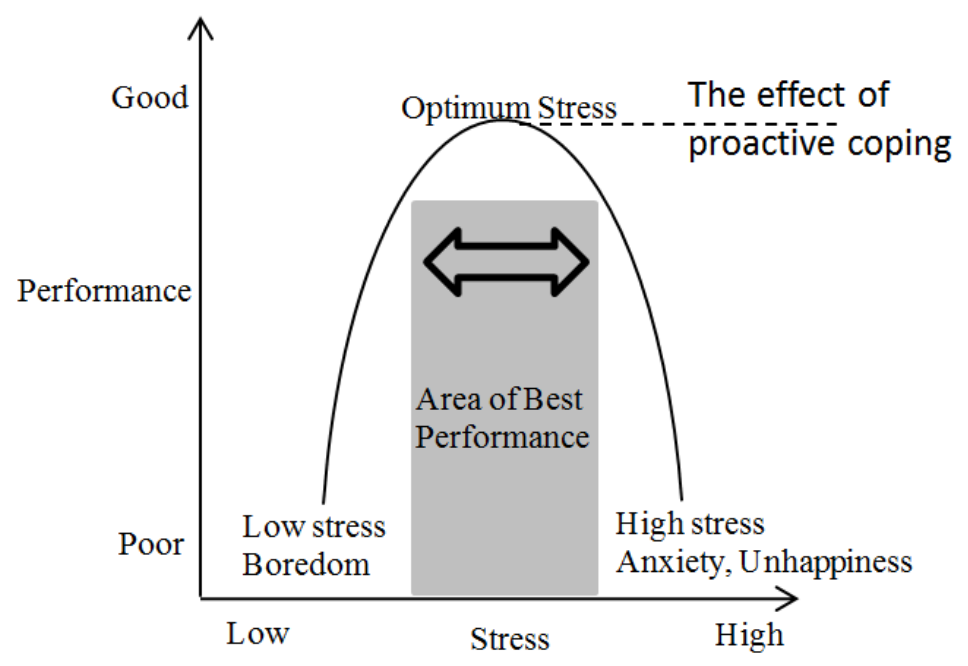

Figure 2. Modified from the Inverted-U model (Yerkes-Dodson Law)

Proactive coping is not only able to maintain high performance under high stress, but also improve positive emotion. The coping strategies must be meaningful in order to generate and sustain positive affection, and the positive affection has the adaptive function (Folkman \& Moskowitz, 2000). According to the broaden-and-build theory of positive emotion, negative emotions will narrow down the attention and make specific action tendencies. On the other hand, positive emotions can expand the focus of attention and the behavioral options, and create social, intellectual property and substantial resources (Fredrickson, 1998, 2001). Fredrickson also points out that positive emotion can be effective in against negative emotion.

In Taiwan, teachers are suffering from long-term perceived work stress. In our study, proactive coping can help teachers enhance the subjective well-being and reduce depression. It's highly recommended that teachers should develop proactive coping strategies to against work stress and increase mental health. Proactive coping is a kind of positive trait, teachers must undergo long-term training in order to internalize it into one's own behavioral mode. We offer following steps for teachers to practice proactive coping. First, use positive thinking to reject pessimism and detect learned helplessness. Second, expand your knowledge space in order to create more feasible solution. Third, list your goals and then break down those big, abstract, and difficult goals into small, specific, and easy targets. Build up your self-efficacy by completing and evaluating the targets. Then, you're equipped with appropriate attitude, knowledge and strategy. Finally, the last step is to believe yourself and face challenges.

Acknowledgements: This work was supported by the Taiwan National Science Council Project No. 102-2410-H-004-191-SS2. 


\section{References}

Anderson, J. C., \& Gerbing, D. W. (1988). Structural equation modeling in practice: A review and recommended two-step approach. Psychological Bulletin, 103(3), 411-423. https://doi.org/10.1037/0033-2909.103.3.411

Arbuckle, J. L. (2011). IBM SPSS Amos 20 user's guide. Armonk, NY: IBM.

Ashforth, B. E., \& Lee, R. T. (1997). Burnout as a process: Commentary on Cordes, Dougherty, and Blum. Journal of Organizational Behavior, 18(6), 703-708. https://doi.org/10.1002/(SICI)1099-1379(199711)18:6<703::AID-JOB847>3.0.CO;2-1

Baron, R. M., \& Kenny, D. A. (1986). The moderator-mediator variable distinction in social psychological research: Conceptual, strategic, and statistical considerations. Journal of Personality and Social Psychology, 51(6), 1173-1182. https://doi.org/10.1037/0022-3514.51.6.1173

Bollen, K. A., \& Stine, R. (1990). Direct and indirect effects: Classical and bootstrap estimates of variability. Sociological Methodology, 20(1), 115-140. https://doi.org/10.2307/271084

Burke, R. J., Greenglass, E. R., \& Schwarzer, R. (1996). Predicting teacher burnout over time: Effects of work stress, social support, and self-doubts on burnout and its consequences. Anxiety, Stress, and Coping, 9(3), 261-275. https://doi.org/10.1080/10615809608249406

Byrne, B. M. (2009). Structural equation modeling with AMOS: Basic concepts, applications, and programming. Oxford England: Routledge.

Chung, P. C., Yu, M. N.,Syu, J. J., Chen, P. L., \& Chao, P. C. (2013). From Languishing to Flourishing: Exploration of the types of teachers' mental health statuses and predictors of teachers' mental health. Bulletin of Educational Psychology, 44(3), 629-646.

Cooper, C. L., Dewe, P. J., \& O'Driscoll, M. P. (2001). Organizational stress: A review and critique of theory, research, and applications. New York, NY: SAGE.

Cordes, C. L., Dougherty, T. W., \& Blum, M. (1997). Patterns of burnout among managers and professionals: A comparison of models. Journal of Organizational Behavior, 18(6), 685-701. https://doi.org/10.1002/(SICI)1099-1379(199711)18:6<685::AID-JOB817>3.0.CO;2-U

Diener, E. (1984). Subjective well-being. Psychological Bulletin, 95, 542-575. https://doi.org/10.1037/0033-2909.95.3.542

Diener, E. (2000). Subjective well-being: The science of happiness and a proposal for a national index. American Psychologist, 55(1), 34-43. https://doi.org/10.1037/0003-066X.55.1.34

Eres, F., \& Atanasoska, T. (2011). Occupational stress of teachers: A comparative study between Turkey and Macedonia. International Journal of Humanities and Social Science, 1(7), 59-65.

Folkman, S., \& Moskowitz, J. T. (2000). Positive affect and the other side of coping. American Psychologist, 55(6), 647-654. https://doi.org/10.1037/0003-066X.55.6.647

Folkman, S., \& Moskowitz, J. T. (2004). Coping: Pitfalls and promise. Annual Review of Psychology, 55, 745-774. https://doi.org/10.1146/annurev.psych.55.090902.141456

Fornell, C., \& Larcker, D. F. (1981). Structural equation models with unobservable variables and measurement error: Algebra and statistics. Journal of Marketing Research, 18(3), 382-388. https://doi.org/10.2307/3150980

Fredrickson, B. L. (1998). What good are positive emotions? Review of General Psychology, 2(3), 300-319. https://doi.org/10.1037/1089-2680.2.3.300

Fredrickson, B. L. (2001). The role of positive emotions in positive psychology: The broaden-and-build theory of positive emotions. American Psychologist, 56(3), 218-226. https://doi.org/10.1037/0003-066X.56.3.218

Golembiewski, R. T., Boudreau, R., Goto, K., \& Murai, T. (1993). Transnational perspectives on job burnout: Replication of phase model results among Japanese respondents. The International Journal of Organizational Analysis, 1(1), 7-27. https://doi.org/10.1108/eb028781

Greenglass , E. R. (2002). Proactive coping and quality of life management. In E. Frydenberg (Ed.), Beyond coping: Meeting goals, visions, and challenges (pp. 37-62). London, England: Oxford University Press. 
Yu, M.-N., Hung, C.-H., \& Lin, C.-W.

https://doi.org/10.1093/med:psych/9780198508144.003.0003

Greenglass, E., Schwarzer, R., Jakubiec, D., Fiksenbaum, L., \& Taubert, S. (1999, July). The proactive coping inventory (PCI): A multidimensional research instrument. In Tytus Sosnowski (Eds.), The 20th International Conference of the Stress and Anxiety Research Society (Vol. 12, pp. 14). Cracow, Poland: FPUW Press.

Hair, J. F., Black, W. C., Babin, B. J., \& Anderson, R. E. (2010). Multivariate data analysis: A global perspective (7th ed.). Upper Saddle River, NJ: Pearson Prentice Hall.

Hopkins, W. S., Hoffman, S. Q., \& Moss, V. D. (1997). Professional development schools and preservice teacher stress. Action in Teacher Education, 18(4), 36-46. https://doi.org/10.1080/01626620.1997.10463362

Hu, L. T., \& Bentler, P. M. (1999). Cutoff criteria for fit indexes in covariance structure analysis: Conventional criteria versus new alternatives. Structural Equation Modeling: A Multidisciplinary Journal, 6(1), 1-55. https://doi.org/10.1080/10705519909540118

Keyes, C. L. M. (1998). Social well-being. Social Psychology Quarterly, 61, 121-140. https://doi.org/10.2307/2787065

Keyes, C. L. M. (2002). The mental health continuum: From languishing to flourishing in life. Journal of Health and Social Behavior, 43(2), 207-222. https://doi.org/10.2307/3090197

Keyes, C. L. M. (2005). Mental illness and/or mental health? Investigating axioms of the complete state model of health. Journal of Consulting and Clinical Psychology, 73(3), 539-548. https://doi.org/10.1037/0022-006X.73.3.539

Keyes, C. L. M., \& Magyar-Moe, J. L. (2003). The measurement and utility of adult subjective well-being. Positive psychological assessment: A handbook of models and measures (pp. 411-426). Washington, DC: American Psychological Association. https://doi.org/10.1037/10612-026

Kokkinos, C. M. (2007). Job stressors, personality, and burnout in primary school teachers. British Journal of Educational Psychology, 77(1), 229-243. https://doi.org/10.1348/000709905X90344

Kyriacou, C. (1987). Teacher stress and burnout: An international review. Educational Research, 29(2), 146-152. https://doi.org/10.1080/0013188870290207

Kyriacou, C. (2001). Teacher stress: Directions for future research. Educational Review, 53, 27-35. https://doi.org/10.1080/00131910120033628

Kyriacou, C., \& Chien, P. (2004). Teacher stress in Taiwanese primary schools. Journal of Educational Enquiry, 5(2), 86-104.

Lazarus, R. S. (1991). Emotion and adaptation. New York: Oxford University Press.

Lazarus, R. S., \& Folkman, S. (1984). Stress, appraisal, and coping. New York, NY: Springer.

MacKinnon, D. P., \& Dwyer, J. H. (1993). Estimating mediated effects in prevention studies. Evaluation Review, 17(2), 144-158.

MacKinnon, D. P., Lockwood, C. M., Hoffman, J. M., West, S. G., \& Sheets, V. (2002). A comparison of methods to test mediation and other intervening variable effects. Psychological Methods, 7(1), 83.

Maslach, C., Schaufeli, W. B., \& Leiter, M. P. (2001). Job burnout. Annual Review of Psychology, 52(1), 397-422.

Muse, L. A., Harris, S. G., \& Feild, H. S. (2003). Has the inverted-U theory of stress and job performance had a fair test? Human Performance, 16(4), 349-364.

Raffety, B. D., Smith, R. E., \& Ptacek, J. T. (1997). Facilitating and debilitating trait anxiety, situational anxiety, and coping with an anticipated stressor: A process analysis. Journal of Personality and Social Psychology, 72(4), 892-906.

Rossi, A. M., Perrewe, P. L., \& Sauter, S. L. (2006). Stress and quality of working life: Current perspectives in occupational health. Charlotte, NC: Information Age Publishing.

Ryff, C. D. (1989). Happiness is everything, or is it? Explorations on the meaning of psychological well-being. Journal of Personality and Social Psychology, 57, 1069-1081. https://doi.org/10.1037/0022-3514.57.6.1069

Ryff, C. D. (1995). Psychological well-being in adult life. Current Direction in Psychological Science, 4, 99-104. https://doi.org/10.1111/1467-8721.ep10772395 
Relationships among perceived work stress, subjective well-being, and depression: Proactive coping as mediator

Ryff, C. D., \& Keyes, C. L. M. (1995). The structure of psychological well-being revisited. Journal of Personality and Social Psychology, 69, 719-727. https://doi.org/10.1037/0022-3514.69.4.719

Schwarzer, R. (2000). Manage stress at work through preventive and proactive coping. The Blackwell handbook of principles of organizational behavior (pp. 342-355). Oxford, England: Blackwell.

Schwarzer, R., \& Knoll, N. (2003). Positive coping: Mastering demands and searching for meaning. Positive psychological assessment: A handbook of models and measures (pp. 393-409). Washington, D.C.: American Psychological Association. https://doi.org/10.1037/10612-025

Shrout, P. E., \& Bolger, N. (2002). Mediation in experimental and nonexperimental studies: New procedures and recommendations. Psychological Methods, 7(4), 422-445. https://doi.org/10.1037/1082-989X.7.4.422

Sobel, M. E. (1982). Asymptotic confidence intervals for indirect effects in structural equation models. Sociological Methodology, 13, 290-313. https://doi.org/10.2307/270723

Stone, C. A., \& Sobel, M. E. (1990). The robustness of estimates of total indirect effects in covariance structure models estimated by maximum. Psychometrika, 55(2), 337-352. https://doi.org/10.1007/BF02295291

Tennant, C. (2001). Work-related stress and depressive disorders. Journal of Psychosomatic Research, 51(5), 697-704. https://doi.org/10.1016/S0022-3999(01)00255-0

Tucker, L. R., \& Lewis, C. (1973). A reliability coefficient for maximum likelihood factor analysis. Psychometrika, 38(1), 1-10. https://doi.org/10.1007/BF02291170

Yanos, P. T. (2001). Proactive coping among persons diagnosed with severe mental illness: An exploratory study. The Journal of Nervous and Mental Disease, 189(2), 121-123. https://doi.org/10.1097/00005053-200102000-00009

Yerkes, R. M., \& Dodson, J. D. (1908). The relation of strength of stimulus to rapidity of habit-formation. Journal of Comparative Neurology and Psychology, 18(5), 459-482. https://doi.org/10.1002/cne.920180503

Yu, M. N., Hsieh, J. C., Lin, S. Y., Chen, P. L., \& Tseng, H. C. (2011a). Confirmatory study of model of teachers' subjective well-being. Psychological Testing, 58(1), 55-85.

Yu, M. N., Huang, H. Y., \& Liu, Y. J. (2011b). The development and psychometric study of Taiwan Depression Scale. Psychological Testing, 58(3), 479-500.

Yu, M. N., Liu, Y. J., \& Li, R. H. (2008). The practical usage of cutoff score in the Taiwanese Depression Scale. Journal of Educational Research and Development, 4(4), 231-258.

Yu, M. N., Syu, J. J., \& Chen, P. L. (2010). The relationship between working hours and depression of elementary and secondary school teachers: Perspective of subjective well-being. Bulletin of Educational Psychology, 42(2), 229-252.

Zedan, R. (2012). Stress and coping strategies among elementary schools teachers in Israel. Universal Journal of Education and General Studies, 1(9), 265-278. 
Yu, M.-N., Hung, C.-H., \& Lin, C.-W. 